Article

\title{
Radar Rainfall Estimation in Morocco: Quality Control and Gauge Adjustment
}

\author{
Zahra Sahlaoui ${ }^{1,2, *(D)}$ and Soumia Mordane 1 \\ 1 LPPPC, Faculty of Sciences Ben M'Sik, University Hassan II, Casablanca 20085, Morocco; \\ mordanesoumia@yahoo.fr \\ 2 CNRMSI, Direction de la Météorologie National, Casablanca 20240, Morocco \\ * Correspondence: sahlaoui_zahra@yahoo.fr; Tel.: +212-6-66820665
}

Received: 25 April 2019; Accepted: 19 May 2019; Published: 23 May 2019

\begin{abstract}
This study focused on investigating the impact of gauge adjustment on the rainfall estimate from a Moroccan C-band weather radar located in Khouribga City. The radar reflectivity underwent a quality check before deployment to retrieve the rainfall amount. The process consisted of clutter identification and the correction of signal attenuation. Thereafter, the radar reflectivity was converted into rainfall depth over a period of $24 \mathrm{~h}$. An assessment of the accuracy of the radar rainfall estimate over the study area showed an overall underestimation when compared to the rain gauges (bias $=-6.4 \mathrm{~mm}$ and root mean square error $[\mathrm{RMSE}]=8.9 \mathrm{~mm}$ ). The adjustment model was applied, and a validation of the adjusted rainfall versus the rain gauges showed a positive impact (bias $=-0.96 \mathrm{~mm}$ and RMSE $=6.7 \mathrm{~mm}$ ). The case study conducted on December 16, 2016 revealed substantial improvements in the precipitation structure and intensity with reference to African Rainfall Climatology version 2 (ARC2) precipitations.
\end{abstract}

Keywords: Moroccan weather radar; rainfall estimate; gauge adjustment; quality control; clutter; signal attenuation; ARC2

\section{Introduction}

Weather hazards, such as heavy rainfall, have a direct impact on human activity, the economy, and safety. In fact, floods are the most widespread and harmful weather-related natural disasters. Therefore, high-resolution precipitation estimates and forecasts are of significant interest for use in hydrological applications, especially in relation to hilly terrain [1-4]. In numerical weather predictions (NWP), scientists are deploying several efforts to improve the ability of their models to forecast heavy rain events [5-7]. As shown by Lopez [8,9] and others [10,11], the assimilation of rainfall measurements in the preparation of accurate initial atmospheric conditions in NWP models has a positive impact.

The standard method of collection for quantifying rainfall on the ground is a rain gauge. However, a gauge is often insufficient because of the high spatial and temporal variability of rainfall, especially in low-density gauge networks. Thus, radar data is widely used to produce a quantitative precipitation estimation (QPE). Owing to their large coverage, high spatial resolution and temporal frequency, weather radars produce observations that adequately represent precipitation structure and evolution. Nevertheless, these radar measurements have limitations [12] that negatively affect the quality of the radar QPE [13,14], such as:

- Beam blockage by obstacles, such as buildings, trees, or mountains, which constitute a mask preventing rain detection.

- Overshooting and partial beam filling, due to the increase of the sounded volume and beam altitude at key distances from the radar. This might lead to underestimation of rain intensity. 
- Clutter, such as echoes from non-meteorological targets like airplanes, birds, insects, and dust particles, which could result in unrealistic precipitation estimations.

- Attenuation of the radar signal, which is the gradual loss of power that occurs during heavy rain. This effect is more important for radars with short wavelengths (e.g., C-band and X-band radars).

Therefore, if a QPE with high precision is required from radar data, it is necessary to develop robust algorithms that deal with these influencing factors, especially clutter and signal attenuation effects [15].

There have been several attempts to combine rain gauges and radar data to enhance the quality of radar rainfall estimates [16-18]. Goudenhoofdt and Delobbe [19] provide a global overview and evaluation of these merging methods. Several national weather services around the world [20-22] produce QPEs based on radar and other data sources like gauges, satellites, and NWP models.

In Morocco, the Moroccan national meteorological service in Khouribga City implemented the first weather radar in 1985. Since 2013, the meteorological service has modernized its weather radar network and it now runs six single-polarization C-band Doppler radars and one dual-polarization C-band Doppler radar [23]. All the radars operate at a range of $250 \mathrm{~km}$, where the radar network enables nowcasting of weather phenomena related to precipitation. Moreover, for QPE, the service has deployed Moroccan weather radars. However, there is an underestimation of the radar QPE when compared to the rain gauge network. Additionally, other weather radar networks worldwide [16] have observed this radar measurement deficiency.

Consequently, one should recognize that a comparison between rain gauges and radar QPEs is not a trivial topic. First, rain gauges provide amounts relative to point accumulations (around $200 \mathrm{~cm}^{2}$ ); whilst the radar QPE corresponds to a volume-averaged rainfall rate. Second, differences between gauge amounts and radar QPEs not only depend on the quality of radar measurements, but also on the quality of the rain gauge data and the density of the network. Therefore, to improve the quality of radar rainfall estimates using a rain gauge depends on good quality gauge data and well-validated merging methods.

In the current work, we present an approach for radar rainfall estimation using the Moroccan C-band radar. First, the radar reflectivity was quality controlled to filter clutter and to correct signal attenuations. Following that, we applied a mixed adjustment model combining radar rainfall and gauge measurements. We also applied the method to 10 rainfall events from November-December 2016, and in January 2017. In our study area, this period corresponded to the winter season-being the rainy season-characterized by an arid to semi-arid climate, with the average annual precipitation amount ranging from $200 \mathrm{~mm}$ to $500 \mathrm{~mm}$.

An overview of the radar and the gauge network used is in Section 2. Section 2 also provides an exhaustive description of the data processing and mixed adjustment models. Section 3 presents and discusses the results, while Section 4 provides the conclusion, along with future areas for development.

\section{Materials and Methods}

\subsection{Data Description}

\subsubsection{C-Band Radar of Khouribga City}

The radar data used in the current study were from an operational single-polarization C-band Doppler radar located in Khouribga City (Figure 1). See Table 1 for further details.

The radar data are used for nowcasting and posterior analysis of extreme weather events over the plains in both the north and west areas of the radar. The southeast area of the radar is covered by the Atlas Mountains, which causes a severe beam blockage. Since the estimation can be very inaccurate at large distances from the radar, a maximum range of $150 \mathrm{~km}$ was used [24]. 


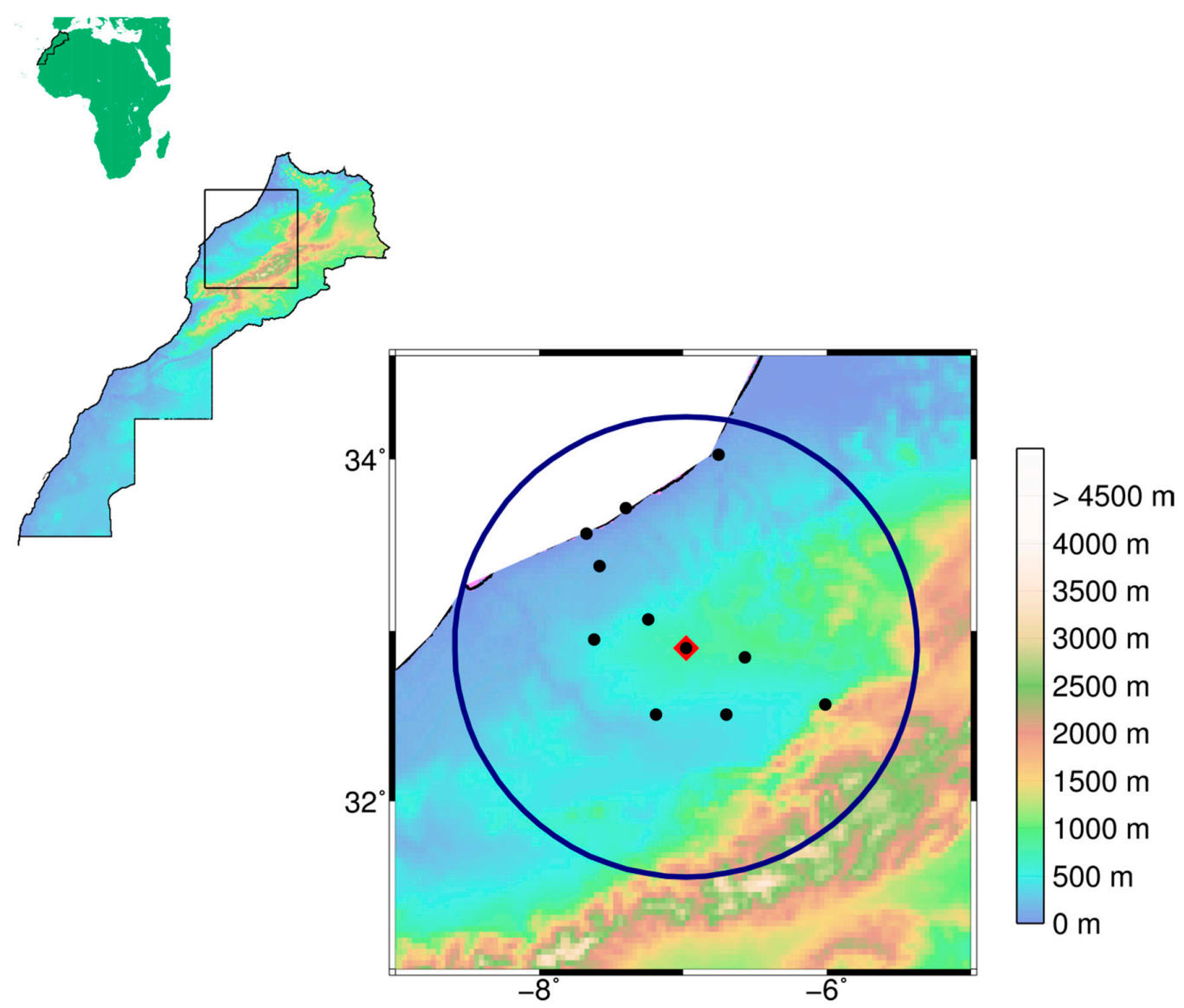

Figure 1. Study area, including orography. The blue circle represents Khouribga City's radar coverage at $150 \mathrm{~km}$, the red diamond refers to the radar's location, whilst the black dots indicate the rain gauges location.

Table 1. Technical specifications of the Khouribga City radar.

\begin{tabular}{cc}
\hline Parameter & Value \\
\hline Latitude & $32.85^{\circ} \mathrm{N}$ \\
Longitude & $6.95^{\circ} \mathrm{W}$ \\
Height & $774 \mathrm{~m}$ \\
Frequency & $5.67 \mathrm{GHz}$ \\
Pulse repetition frequency & $200 \mathrm{~Hz}$ \\
Beam width & $1^{\circ}$ \\
Maximum range & $250 \mathrm{~km}$ \\
Wave length & $0.053 \mathrm{~m}$ \\
Elevations & $0 ; 0.5 ; 1 ; 1.5 ; 2 ; 3 ; 4 ; 9 ; 15 ; 20^{\circ}$ \\
Scanning interval & $10 \mathrm{~min}$ \\
\hline
\end{tabular}

\subsubsection{Rain Gauge Network}

The study area comprised a gauge network containing 11 stations, as shown in Figure 1 . A $24 \mathrm{~h}$ rainfall amount, cumulated from 06:00 UTC day D to 06:00 UTC day D+1, was provided by six synoptic stations and five automatic weather stations (Figure 1). As for the synoptic stations, the rain amounts were measured by an automatic rainfall sensor (AKIM or CIMEL), then validated by the collocated tipping bucket mechanical rain gauge (Precis Mécanique). The data from the automatic weather stations (Metservice) underwent a quality check that consisted of applying climatological thresholds according to the meteorological situation and consistency analysis with the data from surrounding stations. The reception area varied between $200 \mathrm{~cm}^{2}$ and $400 \mathrm{~cm}^{2}$, while the resolution varied between $0.1 \mathrm{~mm}$ and $0.2 \mathrm{~mm}$. 


\subsubsection{The Relationship between Rainfall Rate and Radar Reflectivity}

Weather radars indirectly measure the precipitation amount on the ground. In fact, they measure the power of the electromagnetic signal backscattered by raindrops to the radar antenna. This power is expressed as in Equation (1):

$$
\operatorname{Pr}=\frac{C}{r^{2}} Z
$$

where $\operatorname{Pr}[\mathrm{W}]$ is the received power, $\mathrm{r}[\mathrm{m}]$ is the range from the radar, $\mathrm{C}\left[\mathrm{Wm}^{5} \mathrm{~mm}^{-6}\right]$ is the radar constant and $\mathrm{Z}\left[\mathrm{mm}^{6} \mathrm{~m}^{-3}\right]$ is the reflectivity.

Both the radar reflectivity and rainfall rate, $\mathrm{R}\left[\mathrm{mm} \mathrm{h}^{-1}\right]$, are functions of the raindrop size distribution (Equations (2) and (3)):

$$
\begin{gathered}
\mathrm{Z}=\int_{0}^{D m a x} N_{0} e^{-\Lambda D} D^{6} d D \\
\mathrm{R}=\int_{0}^{D m a x} N(D)\left(\frac{\pi D^{3}}{6}\right) v(D) d D
\end{gathered}
$$

where $\mathrm{N}$ is raindrop distribution $N(D)=N_{0} e^{-\Lambda D}, N_{0}=8000 \mathrm{~m}^{-3} \mathrm{~mm}^{-1}, \Lambda=4.1 \mathrm{R}^{-0.21} \mathrm{~mm}^{-1}$, $\mathrm{D}$ is drop diameter in $\mathrm{mm}$ and $v$ is drop terminal velocity.

Therefore, the relationship between $\mathrm{Z}$ and $\mathrm{R}$ is assumed to follow a power law [25], as expressed by Equation (4):

$$
\mathrm{Z}=a * R^{b}
$$

The coefficients a and $b$ depend on the raindrop size distribution. Different sets of these coefficients were empirically calculated by former studies [26,27] according to the meteorological situation and the hydrometeor type (e.g., rain, snow or hail).

\subsection{Radar-Gauge Merging Method}

\subsubsection{Quality Control of Radar Reflectivity}

The tool wradlib (https://wradlib.org) was used to process data. This tool contains a number of programs that treat radar data for hydrological and meteorological applications. The quality control process consisted of the following steps:

- Clutter detection and filtering: Gabella and Notarpietro [28] proposed an easy-to-implement method based on a two-step algorithm. The first step consists of verifying the spatial consistency for each pixel according to its neighborhood, due to the fact that noisy echoes usually have larger spatial variability compared to the precipitation field. The second step is a test of compactness based on the difference between clutter and rain area/perimeter characteristics. This method produces satisfactory results for C-band radars no matter what the weather conditions are.

- Correction of signal attenuation: The main cause for systematic underestimation of radar rainfall is the attenuation of the radar signal by raindrops, especially in cases of heavy rain. The current study used Kraemer and Verworn's [29] gate-by-gate approach for attenuation correction. This method required no additional inputs (e.g., microwave links or mountain returns) other than the radar reflectivity. The attenuation for the first gate was calculated using the $\mathrm{K}-\mathrm{Z}$ relationship (Equation (5)):

$$
K_{0}=\alpha * Z^{\beta}
$$

The attenuation $K_{0}$ was then used to increase the reflectivity of the gates beyond. For a given gate, $i, K_{i}$ is calculated using the reflectivity $Z_{i}$ and the sum of the attenuation from previous gates (Equation (6)): 


$$
K_{i}=\alpha *\left(Z_{i}+\sum_{j=0}^{i-1} K_{j}\right)^{\beta} * 2 \Delta r
$$

where $\Delta \mathrm{r}=1 \mathrm{~km}$ is the gate length, and coefficients $\alpha$ and $\beta$ are calculated in real time.

First, the "initial guess" values of $1.67 \times 10^{-4}$ and 0.7 were given to $\alpha$ and $\beta$, respectively, which generally produced an overestimation of the attenuation [29]. Then, an iterative algorithm was applied to calculate the optimum $\alpha$ and $\beta$. This method was efficient and did not require any further independent reference for $\alpha$ and $\beta$ calculation.

- Z-R conversion: Due to a lack of information about the hydrometeor's type and the raindrop size distribution of Khouribga City's radar, multiple combinations of a and b were tested, especially those used for the U.S. Weather Surveillance Radar 1988 Doppler (WSR-88D) [30]. The comparison with rain gauges showed that the values $a=75$ and $b=2$ were the most reliable coefficients for the studied rainfall events.

\subsubsection{Gauge Adjustment Model}

The gauge adjustment performed in the current study used a mixed error model [31]. This model assumes that the error $\left(R_{\text {gauge }}-R_{\text {radar }}\right)$ has mainly multiplicative $(\delta)$ contributions for large errors. The additive term $\varepsilon$ is used in case of a small difference between the radar and the gauge (Equation (7)):

$$
R_{\text {gauge }}-R_{\text {radar }}=\delta * R_{\text {radar }}+\varepsilon
$$

The technical implementation is based on a least squares estimation of $\delta$ and $\varepsilon$ for each rain gauge location by minimizing the $\operatorname{sum}\left(\delta^{2}+\varepsilon^{2}\right)$. Therefore, the formulation of $\delta$ and $\varepsilon$ [32] is as follows (Equations (8) and (9)):

$$
\begin{aligned}
& \varepsilon=\frac{R_{\text {gauge }}-R_{\text {radar }}}{R_{\text {radar }}^{2}+1} \\
& \delta=\frac{R_{\text {gauge }}-\varepsilon}{R_{\text {radar }}}-1
\end{aligned}
$$

Using an inverse distance weighting, the coefficients $\varepsilon$ and $\delta$ are then interpolated to the other pixels (Equations (10) and (11)):

$$
\begin{gathered}
\delta_{p}=\frac{\sum_{i=1}^{N} \frac{1}{d} \delta_{i} \delta_{i}}{\sum_{i=1}^{N} \frac{1}{d} i} \\
\varepsilon_{p}=\frac{\sum_{i=1}^{N} \frac{1}{d} \varepsilon_{i}}{\sum_{i=1}^{N} \frac{1}{d} i}
\end{gathered}
$$

where $d_{i}$ is the distance between the radar pixel $\mathrm{p}$ and the $i$ th rain gauge, while $\mathrm{N}$ is the number of rain gauges.

Finally, at the $p$ th pixel, the adjusted radar QPE is given by Equation (12):

$$
R_{a d j}=\left(1+\delta_{p}\right) * R_{\text {radar }}+\varepsilon_{p}
$$

\section{Results and Discussion}

In order to assess the impact of the proposed radar-gauge merging method, a study of 10 winter stratiform precipitation events over November and December 2016 and January 2017 was performed. The meteorological situation was usually characterized by north-to-northwest perturbations, generating light-to-moderate stratiform precipitations over the Moroccan Atlantic coast and plains, in the west of the Atlas Mountains. The maximum observed precipitation amounts for the studied events varied between $10 \mathrm{~mm}$ and $35 \mathrm{~mm}$. 


\subsection{Assessment of Quality Control}

The Khouribga City radar gives reflectivity at 10 elevation angles every $10 \mathrm{~min}$. A quality control was applied to the reflectivity from each elevation angle and at each time step. As explained in the methodology section, it consisted of clutter elimination and signal attenuation correction. The reflectivity was then converted to a rainfall rate using the Z-R relationship. The 10-min deduced rainfall depths were integrated to produce a cumulated rainfall over $24 \mathrm{~h}$. The resulting three-dimensional (3D) field employed polar coordinates. Therefore, geo-referencing was needed to project this 3D field onto the UTM (Universal Transverse Mercator) system. Then, the inverse distance weighting method was applied in order to interpolate the data on a regular grid with $2.5 \mathrm{~km}$ horizontal resolution and $250 \mathrm{~m}$ vertical resolution. Over the study area, the surface altitude varied considerably between the northwest coastal zone, characterized by its lower altitude, and the mountainous region at the southeast. The use of a lower Constant Altitude Plan Position Indicator (CAPPI) would increase the masked area, while the use of a higher CAPPI might worsen the overshooting problem. Consequently, instead of using radar CAPPI at a fixed level, a MAXI-CAPPI was produced. This could be achieved by projecting the vertical maximum of the 3D cumulated rainfall field in a horizontal plane (considered as radar-only QPE).

The radar reflectivity at elevation angle $0^{\circ}$ for December 16, 2016 at 08:30 UTC is presented in Figure 2a. It indicates contamination with clutter, which took the form of a spoke in the north of the radar area. This problem is typically due to WIFI interference, as is the case for long-distance radio telecommunications, wherein WIFI instruments emit waves at a similar frequency to the C-band radar. This interference is very harmful for radar rainfall estimation [33]. The Gabella filter was used to identify and remove WIFI clutter, as shown in Figure 2b,c.

a) Raw Reflectivity (dBZ)

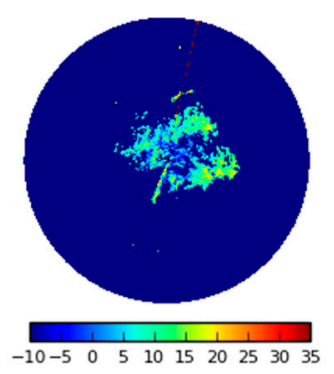

d) Raw Reflectivity (dBZ)

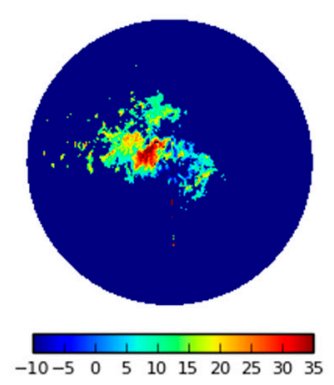

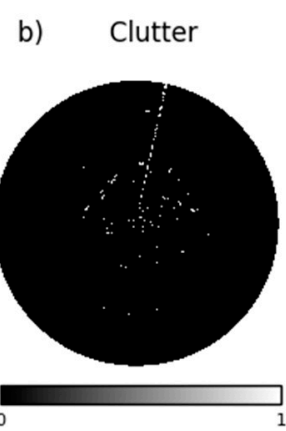

e) PIA (dB)

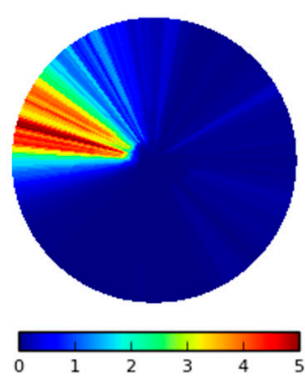

c) Filtred Reflectivity (dBZ)

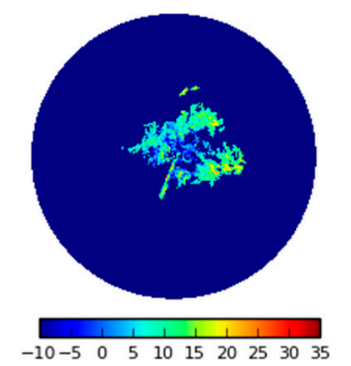

f) Corrected Reflectivity (dBZ)

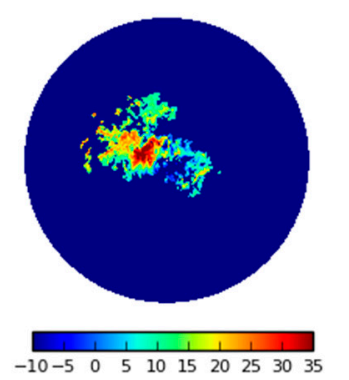

Figure 2. (a) Raw, (b) cluttered and (c) filtered reflectivity pertaining to December 16, 2016 at 08:30 UTC; (d) raw, (e) path-integrated attenuation (PIA) and (f) corrected reflectivity pertaining to December 17, 2016 at 02:20 UTC.

The effectiveness of Kraemer's attenuation correction methodology may be observed in the visualisation of the radar's reflectivity plan position indicator (PPI) at an elevation angle of $0^{\circ}$ and the corresponding path-integrated attenuation (PIA) of December 17, 2016 at 02:20 UTC. Figure 2d depicts 
a cell core of reflectivity with values up to $35 \mathrm{dBZ}$ located near the radar. A correction of up to $5 \mathrm{~dB}$ was performed in the west sector of the radar (Figure 2e) and the corrected reflectivity is shown in Figure $2 f$.

Based on raw reflectivity with no clutter elimination or attenuation correction, Figure 3a shows the $24 \mathrm{~h}$ cumulated precipitations from December 16, 2016 at 06:00 UTC to December 17, 2016 at 06:00 UTC. The clutter caused by WIFI interference creates two spokes of unrealistic (maximum of $120 \mathrm{~mm}$ ) precipitation structures in the north of the radar area. After applying the Gabella filter, this clutter was eliminated, as illustrated in Figure $3 b$.
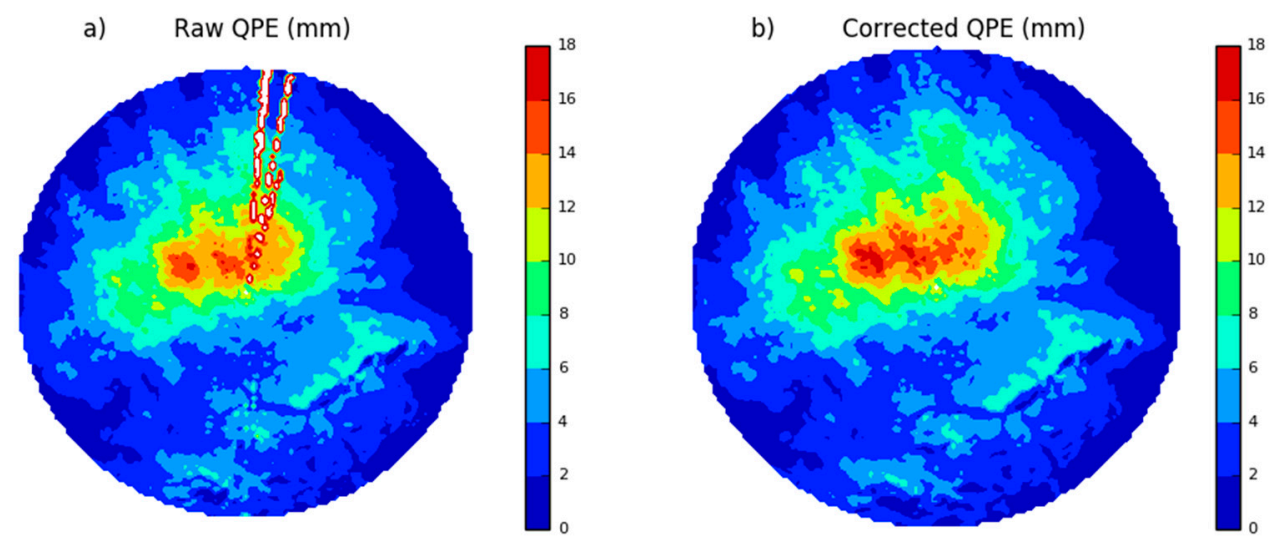

Figure 3. (a) Raw and (b) corrected radar quantitative precipitation estimation (QPE) from December 16, 2016 at 06:00 UTC to December 17, 2016 at 06:00 UTC.

Although the attenuation correction strengthened the precipitation cells locally (near the radar), as shown in Figure 3, there was no substantial correction for the areas in the northeast sector, where rain gauges reached an amount of $35 \mathrm{~mm}$ at Rabat City (130 km distant from the radar). This was probably due to the small amount of precipitation near the radar. Considering the stratiform precipitations studied were mainly generated at low altitude, underestimation of precipitation by the radar QPE could be due to overshooting or partial filling of the radar beam [34]. In addition, the beam width is about $2 \mathrm{~km}$ at $130 \mathrm{~km}$, which can reduce the reflectivity detected in the scan volume and consequently cause underestimation.

\subsection{Validation of the Adjusted Radar Rainfall Estimate}

\subsubsection{General Performances}

Radar-only QPEs ( $24 \mathrm{~h}$ ) were firstly retrieved from the quality checked reflectivity results for the studied events and then used in the adjustment model. For adjusting purposes, the radar rainfall estimate should be calculated at the gauge point. As such, the nearest nine grid points to the gauge location were selected for the radar-only QPEs. The median from this sample was considered as the radar estimated rainfall.

The radar QPE, before and after adjustment, was compared to the rain gauge for 10 rainfall cases. This comparison raised difficult issues; in addition to the quality of both the radar and the gauge's data, numerous factors had an important contribution. The gauge gave measurements of the surface precipitation over an area of about $200 \mathrm{~cm}^{2}$, while the radar estimated the mean precipitation amount of the upper levels of the atmosphere over a $6.25 \mathrm{~km}^{2}$ pixel. Other factors could also be taken into account, such as the precipitation structures, the terrain specifications and the wind-drift effect.

The study area was covered by $24 \mathrm{~h}$ cumulated precipitations provided by 11 rain gauges. The gauge network was used for adjustment with no available additional gauge data for independent validation. Assessment of the quality of the adjusted QPE was performed using a cross-validation. For each event, a "leave-one-out" approach was applied, which meant that one rain gauge was considered as the test case and removed while the adjustment was performed using the remaining gauges. The 
adjusted QPE was then evaluated on the removed gauge. This procedure was repeated for each of the available gauges.

To quantify the estimation error, the root mean square error (RMSE, Equation (13)) and the bias (Equation (14)) were calculated as follows,

$$
\begin{aligned}
\text { RMSE } & =\frac{\sqrt{\sum_{i=1}^{N}\left(R_{\text {radar }}-R_{\text {gauge }}\right)^{2}}}{\mathrm{~N}} \\
\text { Bias } & =\frac{\sum_{i=1}^{N}\left(R_{\text {radar }}-R_{\text {gauge }}\right)}{\mathrm{N}}
\end{aligned}
$$

Figure 4 shows the scatter plots of the dispersion of $24 \mathrm{~h}$ radar-only QPE (Figure $4 \mathrm{a}$ ) and the cross-validation of the adjusted QPE (Figure $4 \mathrm{~b}$ ) versus the rain gauges for all studied events. The radar-only QPE usually underestimates the gauges with a bias of $-6.4 \mathrm{~mm}$ (37\% within a distance of $50 \mathrm{~km}$ ) and a RMSE of $8.9 \mathrm{~mm}$. The use of the radar-gauge merging method brought a substantial improvement. In fact, the cross-validation of the adjusted QPE showed a reduction of the bias to -0.96 $\mathrm{mm}$ and the RMSE to $6.7 \mathrm{~mm}$.
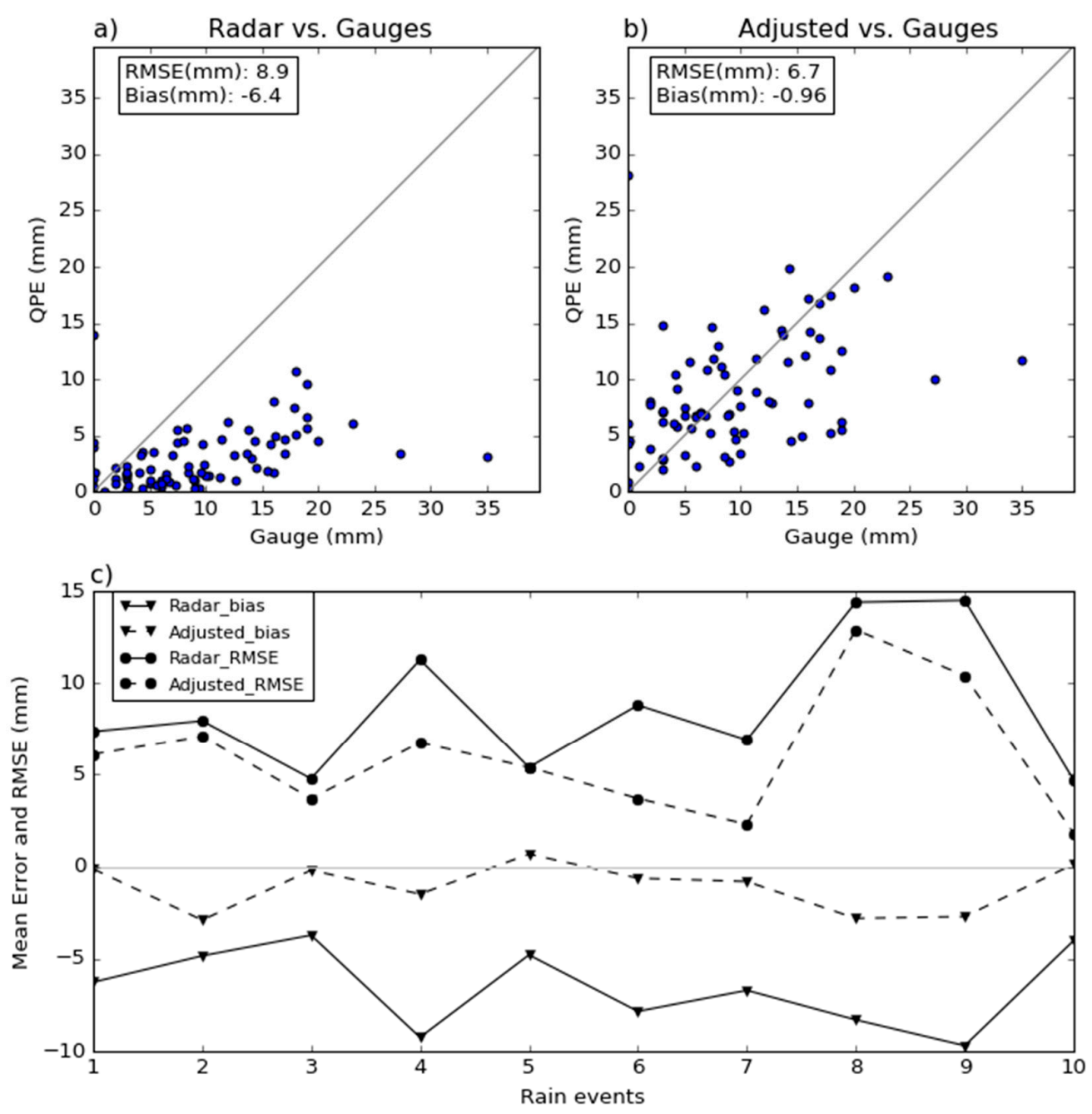

Figure 4. (a) Scatter plots of $24 \mathrm{~h}$ radar-only QPE distribution and (b) the cross-validation of $24 \mathrm{~h}$ adjusted QPE versus the gauge observations for all the studied rainfall events. (c) Statistics in term of bias (triangle) and root mean square error (RMSE) (dot) of the radar-only QPE versus gauges (solid) and cross-validation of the adjusted QPE (dashed) for the 10 studies cases. 
Case-by-case error statistics (bias and RMSE) for cross-validation of the radar-only QPE and the adjusted QPE are presented in Figure 4c. Accordingly, the bias was considerably reduced for all the studied cases. There was also a RMSE improvement for almost all the cases. The enhancement was clear for cases with large errors, such as in 4, 6, 8 and 9. In fact, these events were characterized by an important precipitation amount, especially for gauges more than $100 \mathrm{~km}$ from the radar.

\subsubsection{Case Study}

To assess the effective impact of the adjustment method, the 8th case (held on December 16, 2016) was deeply investigated. This event was characterized by a strong RMSE (14.4 $\mathrm{mm}$ ) and a bias of -8.3 $\mathrm{mm}$. The $24 \mathrm{~h}$ rainfall amounts measured by the rain gauges $\left(\mathrm{R}_{\text {gauge }}\right)$, as well as the radar-only QPE $\left(\mathrm{R}_{\text {radar }}\right)$, are shown in Table 2.

Table 2. Rain gauge measurements, $24 \mathrm{~h}$ radar-only QPE and adjusted QPE cross-validation at different gauge locations for December 16, 2016.

\begin{tabular}{ccccc}
\hline $\begin{array}{c}\text { Gauge Location } \\
\text { (Cities) }\end{array}$ & $\begin{array}{c}\text { Distance from } \\
\text { Radar }(\mathbf{k m})\end{array}$ & Gauge (mm) & $\begin{array}{c}\text { Radar-only } \\
\text { QPE (mm) }\end{array}$ & $\begin{array}{c}\text { Adjusted QPE } \\
\text { Cross-Validation }(\mathbf{m m})\end{array}$ \\
\hline Khouribga & 2.5 & 18 & 10.7 & 5.2 \\
Casablanca & 104 & 18 & 5 & 17.5 \\
Mohammedia & 105 & 20 & 4.5 & 18.2 \\
Nouasseur & 82 & 23 & 6.1 & 19.1 \\
Rabat & 134 & 35 & 3.2 & 11.7 \\
Settat & 63 & 19 & 9.6 & 12.6 \\
Ouad Zem & 68 & 16 & 8 & 7.9 \\
Benhmed & 36 & 0 & 14 & 28.2 \\
Elbrouj & 44 & 0 & 3.9 & 4.2 \\
Ksiba & 104 & 19 & 6.6 & 6.2 \\
Fquih Ben Salah & 44 & 0 & 4.4 & 6.1 \\
\hline
\end{tabular}

The radar-only QPE generally underestimated the rainfall detected by the rain gauges. The distance from the radar increased the underestimation-most notably in the case of Rabat City, located $134 \mathrm{~km}$ from the radar. The cross-validation of the adjusted QPE is also reported in Table 2. The $24 \mathrm{~h}$ adjusted QPE (Figure $4 \mathrm{~d}$ ) fits the gauge data more than the $24 \mathrm{~h}$ radar-only QPE data (Figure $4 \mathrm{c}$ ). Indeed, this improvement was specifically remarked upon for the northwest sector of the radar, which was covered by homogeneous precipitations. However, for some gauges, the cross-validation of the adjusted QPE did not reveal a positive impact; for example, in Khouribga and Benhmed cities. This finding was essentially due to the discontinuous aspect of the precipitation field and the impact of the surrounding gauges.

An independent validation was required to evaluate the relative performance of the proposed radar-gauge merging method. This validation was performed, taking as reference the African Rainfall Climatology version 2 (ARC2) $24 \mathrm{~h}$ cumulated precipitations produced by the Climate Prediction Centre (CPC) of the U.S. National Oceanic and Atmospheric Administration (NOAA).

As described by Novella and Thiaw [35], ARC2 daily precipitation analysis is based on several input sources, specifically rain gauges and geostationary satellite data. Daily binary and graphical output files are produced with a resolution of $0.1^{\circ}$, covering Africa from $40^{\circ}$ south to $40^{\circ}$ north and from $20^{\circ}$ west to $55^{\circ}$ east. Validation with independent gauge data shows that the ARC2 precipitations have an efficient quality and can be used to characterize rainfall events over Africa.

For the studied event, unlike the automatic weather stations, the rain data from synoptic stations were included in the ARC2 precipitations.

Figure 5 presents the validation of the precipitation field regarding the ARC2 data, and shows that the field produced by a linear interpolation of the gauge data (Figure $5 a$ ) gave local information, but was unable to reproduce the precipitation structure over a larger area. The radar-only QPE 
(Figure 5c) strongly underestimated the rainfall amounts. As for the adjusted rainfall field (Figure 5d), it generally matched the ARC2 data (Figure $5 b$ ). In fact, spatial structures and precipitation amounts were improved after adjustment. The adjustment helped to reproduce precipitation cells of more than $20 \mathrm{~mm}$ that were present in the ARC2 product (red ellipses in Figure 5b,d). The adjustment was also useful in strengthening the precipitation amounts, especially in the north of the radar area. Thanks to its high resolution (2.5 km against $10 \mathrm{~km}$ for ARC2), the adjusted QPE showed small-scale structures that could not be identified in the ARC2 rain field. However, an overestimation was observed due to the $35 \mathrm{~mm}$ rain gauge (Rabat City) and the lack of other surrounding rain gauges. At first glance, the $0 \mathrm{~mm}$ observed in Benhmed appeared to be unrealistic. However, the 0 value is coherent with the ARC2 field (Figure $5 b$ ) that did not include this rain gauge in its analysis. The overestimation by the radar QPE was probably due to the use of MAXI-CAPPI.
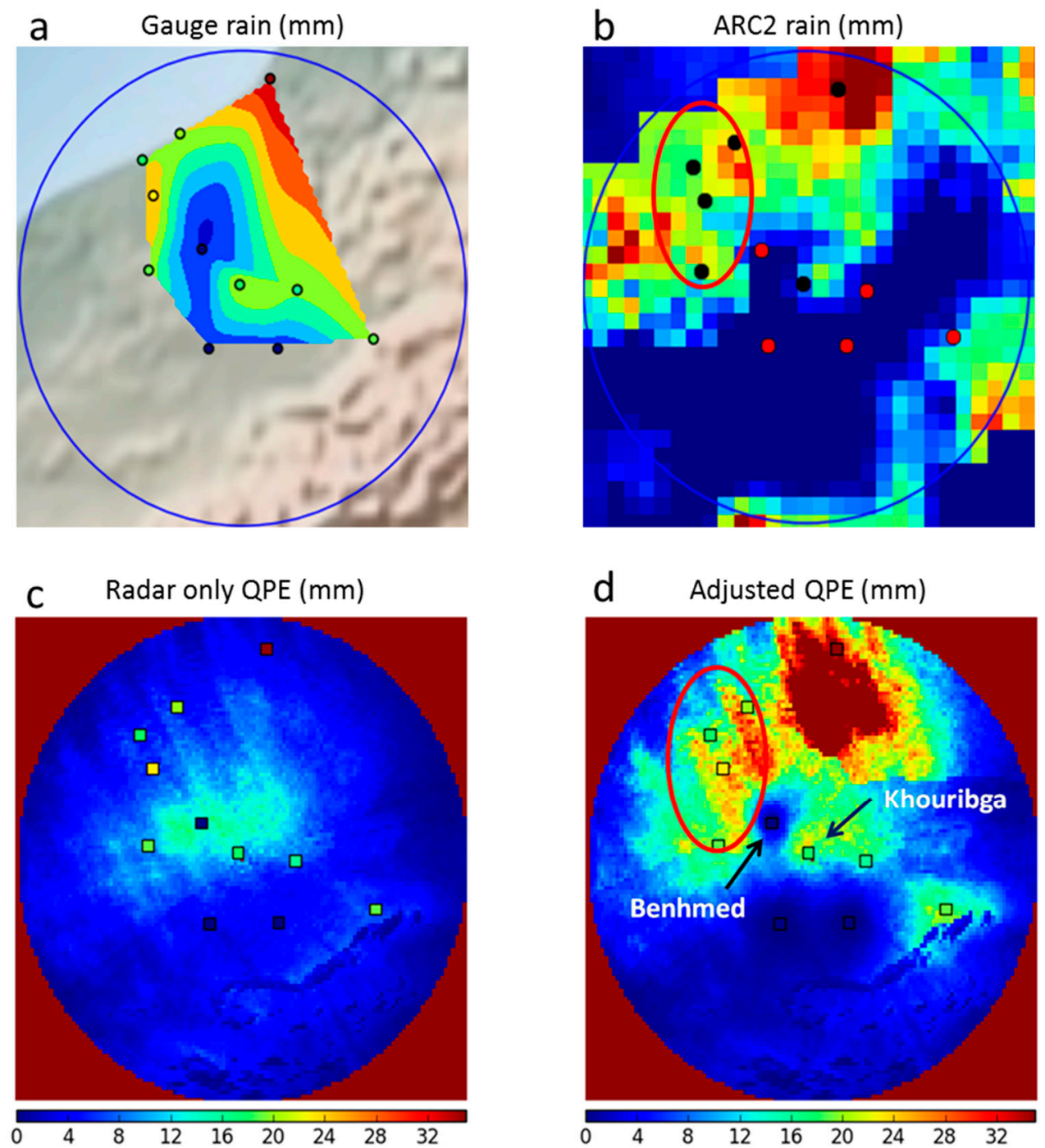

Figure 5. 24 h cumulated precipitations (mm) from December 16, 2016 at 06:00 UTC to December 17, 2016 at 06:00 UTC. (a) Interpolation of the rain gauges, and (b) African Rainfall Climatology version 2 (ARC2) daily precipitation. The black circles are synoptic stations while the red ones are automatic weather stations. (c) Radar-only QPE, and (d) adjusted QPE. The squares represent the rain gauges location colored according to the observed precipitation amount.

The southeast sector of the radar was masked by the Atlas Mountains, which created a beam blockage and prevented a satisfactory detection of the precipitation over this area. The merging 
method was unable to deal with such phenomena, especially with the dearth of gauge observations over the mountains.

\section{Discussion and Conclusions}

The current study aimed to improve the rainfall estimation based on Moroccan weather radars. By applying the Gabella filter, the quality control methodology was able to eliminate WIFI and ground clutter. However, the study of rainfall events over November-December 2016 and in January 2017 showed an underestimation of the radar-only QPE according to the rain gauges. The attenuation correction alone was unable to sufficiently strengthen the precipitation cells far from the radar $(>100 \mathrm{~km})$ since, in all studied cases, there were only light to moderate precipitations near the radar. The underestimation was probably due to an overshooting problem of winter stratiform precipitations, mainly generated at low altitude.

The adjustment based on a mixed model produced improved radar QPE, as shown by the cross-validation of the adjusted QPE versus gauges. The detailed study of the events of December 16, 2016 showed the positive impact of the gauge adjustment and also the sensitivity of the results to the density of the gauge network.

A comparison with ARC2 precipitation analysis revealed that the adjustment method had a positive impact on the precipitation structure and intensity. Indeed, the precipitation cells generally fitted the ARC2 field, especially in the northwest sector, despite an overestimation found near Rabat City due to the lack of surrounding gauges. These findings agree with former studies in similar conditions [4], which also showed a better quality and a relevance of the hydrological applications of adjusted rainfall radars when compared to rain gauges, raw radars or satellites precipitation estimations.

These promising results may certainly be enhanced by the use of a high density gauge network, especially for spatially-discontinuous rainfall events. More case studies should be performed to thoroughly investigate the impact of different hydrometeor types, such as snow or hail, associated with snowfall or orographic precipitations over the Atlas Mountains. In addition, the use of further data sources like satellites and NWP analysis will doubtlessly bring more accuracy to the adjusted QPE. When it comes to a rough terrain like the study area, merging methods [4] or using orographic precipitation climatology [36] should be tested in order to improve the radar rainfall products, particularly when the constraints are specifically related to the orography.

Author Contributions: Investigation, Z.S.; Methodology, Z.S.; Supervision, S.M.; Validation, Z.S. and S.M.; Writing—original draft, Z.S.; Writing—review \& editing, S.M.

Funding: This research received no external funding.

Acknowledgments: The authors are grateful to the reviewers for their comments and suggestions improving the manuscript. The authors also thank Siham Sbii, Fatima-Zahra Hdidou, Khalid Elrhaz, Driss Bari and Mohammed Nabahani for the useful discussions of this work and for their help in revising the manuscript.

Conflicts of Interest: The authors declare no conflict of interest.

\section{References}

1. Germann, U.; Berenguer, M.; Sempere-Torres, D.; Zappa, M. REAL—Ensemble radar precipitation estimation for hydrology in a mountainous region. Q. J. R. Meteorol. Soc. 2009, 135, 445-456. [CrossRef]

2. Harrison, D.L.; Norman, K.; Pierce, C.; Gaussiat, N. Radar products for hydrological applications in the UK. Proc. ICE Water Manag. 2012, 165, 89-103. [CrossRef]

3. Liu, J.; Bray, M.; Han, D. A study on WRF radar data assimilation for hydrological rainfall prediction. Hydrol. Earth Syst. Sci. 2013, 17, 3095-3110. [CrossRef]

4. Gilewski, P.; Nawalany, M. Inter-Comparison of Rain-Gauge, Radar, and Satellite (IMERG GPM) Precipitation Estimates Performance for Rainfall-Runoff Modeling in a Mountainous Catchment in Poland. Water 2018, 10, 1665. [CrossRef]

5. Sokol, Z. Assimilation of extrapolated radar reflectivity into a NWP model and its impact on a precipitation forecast at high resolution. Atmos. Res. 2010, 100, 201-212. [CrossRef] 
6. Wattrelot, E.; Caumont, O.; Mahfouf, J.F. Operational Implementation of the 1D+3D-Var Assimilation Method of Radar Reflectivity Data in the AROME Model. Mon. Weather Rev. 2014, 142, 1852-1873. [CrossRef]

7. Maiello, I.; Ferretti1, R.; Gentile, S.; Montopoli, M.; Picciotti, E.; Marzano, F.S.; Faccani, C. Impact of radar data assimilation for the simulation of a heavy rainfall case in central Italy using WRF-3DVAR. Atmos. Meas. Tech. 2014, 7, 2919-2935. [CrossRef]

8. Lopez, P.; Bauer, P. 1D + 4D-Var assimilation of NCEP stage IV radar and gauge hourly precipitation data at ECMWF. Mon. Weather Rev. 2007, 135, 2506-2524. [CrossRef]

9. Lopez, P. Direct 4D-Var Assimilation of NCEP Stage IV Radar and Gauge Precipitation Data at ECMWF. Mon. Weather Rev. 2011, 139, 2098-2115. [CrossRef]

10. Lien, G.Y.; Kalnay, E.; Miyoshi, T. Effective assimilation of global precipitation: Simulation experiments. Tellus A Dyn. Meteorol. Oceanogr. 2013, 65. [CrossRef]

11. Ban, J.; Liu, Z.; Zhang, X.; Huang, X.Y.; Wang, H. Precipitation data assimilation in WRFDA 4D-Var: Implementation and application to convection-permitting forecasts over United States. Tellus A Dyn. Meteorol. Oceanogr. 2017, 69. [CrossRef]

12. Hunter, S. WSR-88D Radar Rainfall Estimation: Capabilities, Limitations and Potential Improvements. Natl. Weather Dig. 1996, 20, 26-38.

13. Villarini, G.; Krajewski, W.F. Review of the different sources of uncertainty in single polarization radar-based estimates of rainfall. Surv. Geophys. 2010, 31, 107-129. [CrossRef]

14. Berne, A.; Krajewski, W.F. Radar for hydrology: Unfulfilled promise or unrecognized potential? Adv. Water Resour. 2013, 51, 357-366. [CrossRef]

15. Faure, D.; Auchet, P.; Engasser, E. Attenuation caused by direct rainfall on a C band radar: 1998 campaign of measurements in Nancy. In Proceedings of the 3th International Workshop on Rainfall in Urban Areas, Pontresina, Switzerland, 10-13 December 2000; pp. 171-176.

16. Harrison, D.L.; Driscoll, S.J.; Kitchen, M. Improving precipitation estimates from weather radar using quality control and correction techniques. Meteorol. Appl. 2000, 6, 135-144. [CrossRef]

17. Delrieu, G.; Wijbrans, A.; Boudevillain, B.; Faure, D.; Bonnifait, L.; Kirstetter, P.E. Geostatistical radar-rain gauge merging: A novel method for the quantification of rain estimation accuracy. Adv. Water Resour. 2014, 71, 110-124. [CrossRef]

18. Jewell, S.A.; Gaussiat, N. An Assessment of Kriging Based Rain-Gauge-Radar Merging Techniques. Q. J. R. Meteorol. Soc. 2015, 141, 2300-2313. [CrossRef]

19. Goudenhoofdt, E.; Delobbe, L. Evaluation of radar-gauge merging methods for quantitative precipitation estimates. Hydrol. Earth Syst. Sci. 2009, 13, 195-203. [CrossRef]

20. Tabary, P. The new French radar rainfall product. Part I: Methodology. Weather Forecast. 2007, 22, $393-408$. [CrossRef]

21. Tabary, P.; Desplats, J.; Do Khac, K.; Eideliman, F.; Gueguen, C.; Heinrich, J.-C. The new French radar rainfall product. Part II: Validation. Weather Forecast. 2007, 22, 409-427. [CrossRef]

22. Zhang, J.; Howard, K.; Langston, C.; Vasiloff, S.; Kaney, B.; Arthur, A.; Van Cooten, S.; Kelleher, K.; Kitzmiller, D.; Ding, F.; et al. National Mosaic and Multi-sensor QPE (NMQ) System: Description, Results, and Future Plans. Bull. Amer. Meteor. Soc. 2011, 92, 1321-1338. [CrossRef]

23. Malkomes, M. The Morocco Weather Radar Network mix of upgraded radars and new ones-A success story. In Proceedings of the 8th Eutopean Conference on Radar in Meteorology and Hydrology, Garmisch-Partenkirchen, Germany, 1-5 September 2014.

24. Salek, M.; Novak, D. Operational application of combined radar and rain gauges precipitation estimation at the CHMI. In Proceedings of the 3th European Conference on Radar in Meteorology, Visby, Sweden, 6-10 September 2004; ERAD Publication Series 2. pp. 16-20.

25. Marshall, J.S.; Palmer, W.M. The distribution of raindrop with size. J. Meteorol. 1948, 5, 165-166. [CrossRef]

26. Chapon, B.; Delrieu, G.; Gosset, M.; Boudevillain, B. Variability of raindrop size distribution and its effect on the Z-R relationship: A case study for intense Mediterranean rainfall. Atmos. Res. 2008, 87, 52-65. [CrossRef]

27. Uijlenhoet, R. Raindrop size distributions and radar reflectivity-rain rate relationships for radar hydrology. Hydrol. Earth Syst. Sci. 2001, 5, 615-628. [CrossRef]

28. Gabella, M.; Notarpietro, E. Ground clutter characterization and elimination in mountainous terrain. In Proceedings of the 2nd European Conference on Radar in Meteorology and Hydrology, Delft, The Netherlands, 18-22 November 2002; pp. 303-311. 
29. Kraemer, S.; Verworn, H.R. Improved C-band radar data processing for real time control of urban drainage systems. In Proceedings of the 11th International Conference on Urban Drainage, Edinburgh, Scotland, UK, 31 August-5 September 2008.

30. Chilson, P.B. "Z-R relationships”, Weather Radar Applications ECE/METR 5683. 2008. Available online: http://www.ou.edu/radar/z_r_relationships.pdf (accessed on 23 May 2019).

31. Heistermann, M.; Jacobi, S.; Pfaff, T. Technical Note: An open source library for processing weather radar data (wradlib). Hydrol. Earth Syst. Sci. 2013, 17, 863-871. [CrossRef]

32. Pfaff, T. Radargestuetzte Schaetzung von Niederschlagsensembles. Operationelle Abfluss-und Hochwasservorhersage in Quellgebieten. Final Project Report. University of Stuttgart: Stuttgart, Germany; pp. 113-118. Available online: http://www.rimax-hochwasser.de/fileadmin/user_uploads/RIMAX_PUB_22_ 0015_Abschlussbericht\%20OPAQUE_final.pdf (accessed on 23 July 2018). (In German).

33. Scovell, R.; Gaussiat, N.; Matthews, M. Recent Improvements to the Quality Control of Radar Data for the OPERA Data Centre. In Proceedings of the 36th radar conference of American Meteorological Society, Breckenridge, CO, USA, 16-20 September 2013.

34. Delobbe, L. Estimation des Précipitations à L'aide d'un Radar Météorologique; Scientific and technical publication. $\mathrm{Nr} 44$; Royal Meteorological Institute of Belgium: Brussels, Belgium, 2006. (In French)

35. Novella, N.S.; Thiaw, W.M. African rainfall climatology version 2 for famine early warning systems. J. Appl. Meteor. Climatol. 2013, 52, 588-606. [CrossRef]

36. Zhang, J.; Qi, Y.; Langston, C.; Kaney, B.; Howard, K. A real-time algorithm for merging radar QPEs with rain gauge observations and orographic precipitation climatology. J. Hydrometeorol. 2014, 15, 1794-1809. [CrossRef]

(C) 2019 by the authors. Licensee MDPI, Basel, Switzerland. This article is an open access article distributed under the terms and conditions of the Creative Commons Attribution (CC BY) license (http://creativecommons.org/licenses/by/4.0/). 